\title{
CORRESPONDENCE
}

Merit awards

G de Lacey, FRCR.. 1125

Reference values for $75 \mathrm{~g}$ oral glucose

tolerance test in pregnancy

H W Sutherland, FRCOG, and D W M Pearson, MB; I S Ross; K J Dennis, FRCOG; N J Morrish, MRCP ...................................... 1125

How informed is signed consent?

N Warnock, MRCP; M Gough, FRCS ........... 1126

Viral infection, human papillomavirus DNA and cervical neoplasia

P Walker, MRCOG, and others

Effect of wheat bran on weight of stool

K W Heaton, FRCP; S A Müller-Lissner, MD;

J A Barrett, MRCP........................... 1127
Modern medicine and war

L M Lovett, MRCPSYCH, and J W T Lovett,

MRCPSYCH.................................. 1128

Passive smoking and lung cancer: a

publication bias?

A J Wells, PHD ............................. 1128

The Biopty cut procedure for renal biopsies

J C Mackenzie, FRCP, and others ............... 1128

Health of long term benzodiazepine users

PHalfon, MD, and others ..................... 1129

A better deal for senior house officers

A H Meakin, MRCGP, and others .............. 1129

Medical researchers in general practice

W O Williams, FRCGP ........................ 1129

Alive and well

R A Risdon, FRCPATH, and others ............. 1130 $\beta$ Blockers, lipids, and coronary

atherosclerosis

H Chamsi-Pasha, MRCP, and others; J Coope, FRCGP, and T S Warrender, MB ................. 1130

Drug point Danger of interaction between ciprofloxacin and theophylline (J L Bem and R D Mann) ............................... 1131

Points Inappropriate dental care in casualty departments (A Seymour); Laparoscopic incisions at the lower umbilical verge (H Reiss, G T Watts); Elastic stockings (D C Holloway); Availability of proper officers (D F M Thomas)

Notice of inadvertent repetitive publication

(S Mindel) .............................. 1130

All letters must be typed with double spacing and signed by all authors.

- No letter should be more than 400 words.

- For letters on scientific subjects we normally reserve our correspondence columns for those relating to issues discussed recently (within six weeks) in the BMF.

- We do not routinely acknowledge letters. Please send a stamped addressed envelope if you would like an acknowledgment.

- Because we receive many more letters than we can publish we may shorten those we do print, particularly when we receive several on the same subject.

\section{Merit awards}

SIR,-It is a relief to find at last a defence of the merit award system (Dr Richard White, 12 March, p 791). Clearly anyone prepared to advocate this Byzantine system of consultants distributing among themselves $£ 60 \mathrm{~m}$ of public money annually must know a lot more about it than his letter has told us. Will his next letter provide us with a deus ex machina with which to silence all doubting Thomases, perhaps enlightening us as to the mystical procedures leading to a higher award?

Nevertheless, it will certainly be reassuring to his consultant colleagues in Birmingham that in their hospital they elect a district nomination committee of five from the various divisions. But how typical is this sensible mechanism? For example, in our district four divisional chairmen (there may well be more) with a total of 10 years' service on the medical executive committee had rarely known who the district award representatives were, nor had any of them ever been sounded about colleagues available for nomination. Whereabouts is this "endless consultation with colleagues"? Are we so perspicacious in the south that we can do away with such time consuming niceties?

After labelling Dr Roger Gabriel (13 February, p 501) as "misguided and cynical" for daring to suggest that selection for an award might depend on "not what you do but who you know," Dr White wonders if Dr Gabriel has any personal experience of the selection procedure? Are the uninitiated among us unqualified to pass comment? Do consultants need to be MPs before they can criticise the government? Dr White goes on to state that most doctors want the committees' deliberations to remain secret. Where is his evidence? Might silence on the whole question of secrecy, soundings, consultations, and deliberations be due more to ignorance of the mysterious intricacies of the system or to collaboration by default on the part of most doctors hoping for an award by not rocking the boat until they achieve success at 48? After that, of course, continued silence might not be unrelated to the tantalising thought of the next possibility . . . a higher award.

But Dr White may be responsible unwittingly for causing the late Lord Spens to turn in his grave. Here is this experienced representative (presently serving on a higher awards committee) demonstrating how he chooses to rewrite the fundamental, indeed only, justification for a large and arbitrary pay rise. The Spens Committee (1948) emphasised that we select "individual specialists whose outstanding distinction merits additional reward." Dr White, however, is happy to justify the slow acquisition of a $\mathrm{C}$ award by teaching hospital consultants because their "potential for a higher award is greater than that of non-teaching colleagues." Has the system been redesigned to reward lack of potential? Are we penalising (how ever temporarily) "outstanding distinction"? Clearly, we must no longer take seriously state ments that "seniority alone is not grounds for an award and age is no bar."

But though Dr White is quick to disparage Dr Gabriel's status as critic, he singularly fails to address the very serious allegations recently made by Dr Rita Henryk-Gutt (9 January, p 129). Dr Henryk-Gutt (as Drs Lester ${ }^{3}$ and Bruggen and Bourne ${ }^{4}$ before her) indicates clearly that discrimination against women continues to be blatant Recently, the $B M \mathcal{F}$ was severely critical of a London medical school for discriminating against female students as well as members of ethnic minorities (5 March, p 657). But is there not an equally large blot on the profession resulting from the overt discrimination of consultants against their female colleagues? This casual attitude to female consultants is well illustrated by the surprising lack of knowledge of a previous chairman of the Central Advisory Committee on Distinction Awards, who in 1981 told the House of Commons
Social Services Committee that after five years as chairman in regard to sexual discrimination he "did not realise the figures actually." He further stated that never once in all his attendances at award advisory committees had he heard the sex of a consultant discussed. This is, of course, the heart of the problem. Patronage, bias, and discrimination begin at district level, where nominations originate. Unless very stringent safeguards against sloppy (and occasionally improper) practice are introduced at hospital level then sexual discrimination and other abuses will occur. There may well be safeguards built into selection in Birmingham, but Dr White is naive if he believes that a more clearly defined constitution is not urgently required elsewhere. $^{6}$

Northwick Park Hospital,

Harrow, Middlesex HA1 3U

1 Spens Committee. Report of the inter-departmental committee on the remuneration of consultants and specialists. London: HMSO, 1948. (CMD 7420 .)

2 Clayton S. Procedures and criteria for selection for distinctio and meritorious service awards. Health Trends 1979;4:73-6.

3 Lester E. Sex distribution of distinction awards. $\mathrm{Br} \mathrm{Med} \mathcal{J}$ 1980;280:198.

4 Bruggen $P$, Bourne $S$. The distinction awards system in England and Wales 1980. Br Med f 1982;284:1577-80.

5 Clayton S. In: The Social Services Select Committee report into medical education. (HC31, 1980-1.)

6 de Lacey G, Liberman M. Disappearing distinction. Lancet 1988;ii:697-8.

\section{Reference values for $\mathbf{7 5} \mathbf{g}$ oral glucose} tolerance test in pregnancy

SIR,-May we urge your readers to be cautious in their appraisal of the paper by $\mathrm{Mr} \mathrm{M}$ Hatem and others (5 March, p 676).

The "Southampton population" was deliberately selected by excluding from the study those with a wide variety of risk factors for gestational 
diabetes mellitus, which surely destroys the value of the data as reference standards. The fact that all the babies were healthy bears testimony to the high degree of selection of the study group. Moreover, maternal age is a major influence in the glycaemic response to the oral glucose tolerance test in pregnancy, yet being over 35 years was an exclusion factor in case selection.

The differential between venous plasma glucose concentrations at the 60 and 120 minute samples was remarkably small $(0.11$ and $0.6 \mathrm{mmol} / 1$ in groups 1 and merged groups 2 and 3 respectively). This may also be a reflection of the supernormal "population" selected for study. We have performed investigations of oral glucose tolerance test values in unselected groups of pregnant women (excluding only those with insulin dependent diabetes mellitus or taking corticosteroids); these have shown differences between the one and two hour glucose values of $0.9-1.5 \mathrm{mmol} / 1$, results in line with the $100 \mathrm{~g}$ and $50 \mathrm{~g}$ studies of O'Sullivan and Mahan and those of Abell and Beischer. ${ }^{12}$ These factors lead us to suspect that both the 60 and 120 minute mean values may be too low and the 60 minute value particularly so.

The Southampton group has usefully brought to our attention the paucity of data available for the $75 \mathrm{~g}$ oral glucose tolerance test in pregnancy and has whetted the appetite for the publication of the multicentre European study initiated in the diabetic pregnancy study group of the European Association for the Study of Diabetes. We hope that that study will stand the test of close scrutiny and fulfil the promise of the title of the Southampton paper. Aberdeen AB9 2ZA

O'Sullivan JB, Mahan C. Criteria for the oral glucose tolerance test in pregnancy. Diabetes 1964;13:278-85.

2 Abell DA, Beischer NA. Evaluation of the 3 hour oral glucose tolerance test in detection of hyperglycaemia in pregnancy. Diabetes 1975;24:874-80.

SIR, $-M r$ M Hatem and colleagues (5 March, p 676) point to the association between hyperglycaemia in pregnancy and intrauterine death and fetal malformation. In proposing upper limits of normal for glucose tolerance defined by the $97 \cdot 5$ centile of their population are the authors implying that values above this limit are abnorma and associated with fetopathy?

It seems difficult to propose reference values for glucose tolerance in pregnancy when the population used to derive these reference values did not show any fetopathy in the group defined by the authors as being above the upper limit of normal. No data are presented for pathological findings in the outcome of pregnancies in women who showed glucose tolerance above this cut off point.

Surely the important values for glucose tolerance in pregnancy are those which can be associated with pathological change in the fetus. Such values cannot be determined by statistical analysis of the variability of glucose tolerance in a normal population but could be determined by a study which attempts to correlate glucose tolerance with fetal outcome. The correlation between glucose tolerance and fetopathy may be continuous throughout the range of maternal glucose tolerance, allowing the conclusion that glucose tolerance is not of good predictive value in individual cases. ${ }^{1}$

I S Ross

Department of Clinical Biochemistry, Aberdeen Royal Infirmary, Aberdeen
Farmer G, Russell G, Hamilton DRN, et al. The influence of maternal glucose metabolism on fetal growth, development, and morbidity in 917 simpleton pregnancies in non-diabetic women. Diabetologia (in press).

AUTHOR'S REPLY - Our paper made no claim about the recognition of fetopathy. The most efficient method of testing for glucose intolerance in pregnancy remains controversial, but the WHO expert committee has proposed that a $75 \mathrm{~g}$ ora glucose tolerance test should be used. ${ }^{\prime}$ It is therefore necessary to determine the response of pregnant women to this challenge. Our objective was simply to help to answer the question posed by the committee.

Since we aimed to show the response to the glucose load of normal pregnant women we excluded women from our sample according to those criteria that are generally accepted to indicate a higher risk of developing impaired glucose tolerance in late pregnancy.

Apart from the diabetic woman mentioned in our paper, there were no serious fetopathies in ou subjects. In particular, all babies were liveborn and free from major congenital abnormalities and none had any features giving rise to clinical suspicion of neonatal hypoglycaemia. Subjects given a $75 \mathrm{~g}$ ora glucose tolerance test and showing values within our "normal" range are therefore unlikely to show diabetic fetopathy.

We agree with Dr Ross, however, that a total population study is needed to show the predictive value of oral glucose tolerance test results for an abnormal outcome of pregnancy.

Department of Human Reproduction

K JOHN DENNIS

and Obstetrics,

Princess Anne Hospital,

Southampton SO9 4HA

1 World Health Organisation Expert Committee on Diabetes Mellitus. 2nd Report. Geneva: WHO, 1980. (Technical Report Series No 646.)

SIR,-While I agree with $\mathrm{Mr} \mathbf{M}$ Hatem and his colleagues ( 5 March, p 676) that there is a lack of data on the $75 \mathrm{~g}$ oral glucose tolerance test in pregnancy and that the current World Health Organisation criteria for diabetes mellitus and impaired glucose tolerance may not be the righ values to use in pregnancy, the conclusions they draw from their study may be misleading.

They recommend upper limits of normal for their "Southampton population" based on the geometric mean values and standard deviations of oral glucose tolerance tests in women in the last two trimesters of pregnancy. While this approach may be of use in defining a reference range for biochemical assay I would question its suitability for the definition of diabetes. The WHO criteria are based on the demonstration of increased risk in epidemiological studies: the criteria for abnorma glucose tolerance in pregnancy should similarly be based on demonstrated risk in terms of the outcom of pregnancy. An alternative view of this study is that instead of providing evidence for an upward revision of the diagnostic levels it shows once again that abnormal glucose tolerance is more common in pregnancy. Indeed there are reports that sugges that women with glucose values below those currently recommended (albeit on the criteria used in the United States, which are broadly equivalen to the WHO definitions of diabetes mellitus and impaired glucose tolerance combined) may be at risk in terms of an adverse outcome of pregnancy. ${ }^{12}$

Unit for Metabolic Medicine

United Medical and Dental Schools of Guy's and St Thomas's Hospitals, London SE1 9RT

N J MORRISH
Tallarigo L, Giampietro O, Penno G, et al. Relation of glucose tolerance to complications of pregnancy in nondiabetic women. N Engl f Med 1986;16:989-92.

2 Langer O, Brustman L, Anaegbunam A, et al. The significance of one abnormal glucose tolerance test value on adverse outcome in pregnancy. Am f Obstet Gynecol 1987;157:758-63.

\section{How informed is signed consent?}

SIR,-Mr D J Byrne and others (19 March, p 839) raise an important question in asking "How informed is signed consent?" Unfortunately, they not only misunderstand or misquote the law relating to consent but are reluctant to accept the possibility that doctors themselves are to blame for patients' poor understanding of the surgery they have undergone.

They state that "the signed consent form fulfils a legal requirement." This is not the case. Before any examination, procedure, or surgical operation the doctor requires the informed consent of the patient or he may be guilty of an assault. This may be given orally or sometimes merely implied by the presence of the patient at his doctor's office. At other times, notably in the case of surgery, it may be prudent for the doctor to have some record of having obtained the patient's informed consent to help him defend a subsequent action by a patient claiming that such consent was not given. This is the purpose of the consent form. It is not a legal requirement, since a doctor may well be able to prove by other means-for instance, by the evidence of witnesses-that the patient did understand the nature and effects of surgery and agreed to them. Conversely, the mere existence of a consent form does not provide legal protection from prosecution if the patient did not know or did not understand what he was signing. The authors have gone some way to showing that signed consent does not necessarily imply the legally required informed consent, and indeed future litigants may well cite the paper as background evidence of the lax procedures of the medical profession.

A number of explanations, including failing memory and the effect of sedative drugs, are suggested for the patients' poor knowledge of their surgery when tested postoperatively. While these factors may be at work, the mere fact of poor knowledge at this stage would not concern a court, and nor is it a reason to concern a younger relative in the giving of consent. Provided the patient gave true informed consent at the time the legal requirement has been fulfilled. Future research could more usefully be directed at finding out what patients know before their surgery takes place. Experience of listening to fellow doctors obtaining signatures and review of my own performance when I was a novice house surgeon lead me to fear that inadequate, hurried explanations and failure to translate medical jargon into plain English would loom high on the list of reasons for poor understanding by patients.

Doctors wishing to research their own communication skills and to protect themselves at the same time would do well to conclude the "consenting" formalities by asking the patient to explain the proposed procedure back to them and to record their success in the case notes

\section{NiALL WARNOCK}

Royal Hallamshire Hospital,

Sheffield S10 INX

SIR,-The article by Mr D J Byrne and his coauthors reminds us once more of the difficulties of ensuring that patients understand the nature of the operation they are to undergo or have under- 